\title{
Organo-Clay Formulations of the Hydrophobic Herbicide Norflurazon Yield Reduced Leaching
}

\author{
Tomás Undabeytia, ${ }^{*},+$ Shlomo Nir, ${ }^{\dagger}$ and Baruch Rubin ${ }^{\ddagger}$ \\ Seagram Center for Soil and Water Sciences, and Department of Field Crops, Vegetables and Genetics, \\ Faculty of Agricultural, Food and Environmental Quality Sciences, The Hebrew University of J erusalem, \\ P.O. Box 12, Rehovot 76100, Israel
}

The study aimed to reduce leaching of the hydrophobic herbicide norflurazon (4-chloro-5methylamino-2-( $\alpha, \alpha, \alpha)$-trifluoro-m-tolylpyridazin-3-(2H)-one) by adsorbing it on clays or organoclays. The surface of the clay mineral montmorillonite was modified from hydrophilic to hydrophobic by preadsorbing it with organic cations, of which thi oflavin-T (TFT) at a loading corresponding to $5 / 8$ of the cation-exchange capacity of the clay mineral yielded the highest affinity of adsorption of norflurazon. Pillared clay (PC) used without organic cations exhibited enhanced affinity for norflurazon adsorption, much higher than that of montmorillonite or sepiolite. Fourier transform infrared (FTIR) results showed interactions between aromatic moieties of preadsorbed TFT and the herbicide. Stronger interaction of the herbicide with a clay mineral or organo-clay corresponded to its slower release. Formulations prepared on the basis of montmorillonite-TFT and PC were more effective in reducing herbicide leaching in soil columns in comparison to the commercial formulation, whereas the herbicidal efficiencies were comparable.

Keywords: Norflurazon; thioflavin T; montmorillonite; pillared clay; leaching

\section{INTRODUCTION}

Norflurazon is a preemergence selective herbicide for weed control in citrus, cotton, cranberries, nuts, pome fruits, and stone fruits. Its primary mode of action is the inhibition of phytoene desaturase, a step in the basic dehydrogenation in the carotenoid biosynthesis. However, the inhibition of carotenoid synthesis is a secondary effect, the chlorophyll being destroyed by photooxidation (Lo and Merkle, 1984).

Norflurazon retention in soils is related directly to the organic matter content (William et al., 1997), being subject to considerable leaching in porous soils with low organic matter contents (Reddy et al., 1992). Leaching of herbicides to the deep soil layers is a topic with a growing interest, because of its potential for groundwater contamination (Franklin et al., 1994; Kim and Feagley, 1998). Monitoring of groundwater contamination across the United States of America (U.S.A.) registered the occurrence of 17 pesticides in groundwater whose levels exceeded the lifetime health advisory level (Parsons and Witt, 1988). On the other hand, depending on the hydraulic gradients, contaminated surface water may affect groundwater quality. Norflurazon has been detected in studies monitoring groundwater for pesticides at selected mixing/loading sites in Arkansas (Senseman et al., 1997a). In a pesticide survey of surface water in Arkansas, norflurazon was one of the most commonly detected herbicides, i.e., $16 \%$ of the total detections (Senseman et al., 1997b).

To decrease the environmental risk, several strategies are empl oyed to reduce the amount of herbicide applied,

* Institute of Natural Resources and Agrobiology, Apdo. 1052, 41080 Sevilla, Spain. Telephone: +34-954624711. Fax: +34-954624002. E-mail: undabeyt@irnase.csic.es.

† Seagram Center for Soil and Water Sciences.

‡ Department of Field Crops. such as integrated pest management, and controlled release formulations (CRFs) (Boydston, 1992; Wilcut et al. 1997). Several approaches have been employed to obtain CRFs: alginate encapsulation (Gerstl et al., 1998), cyclodextrin complexation (Loukas et al., 1994), polymeric microcapsules (Dailey et al., 1993), lignin entrapment (Ferraz et al., 1997), and starch encapsulation (Mervosh et al., 1995). This latter was essayed for norflurazon (Boydston, 1992).

This study aimed to develop CRFs of the herbicide norflurazon by using organo-clays. The approach used was to modify the clay surface from hydrophilic to hydrophobic by preadsorbing suitable organic cations (J aynes and Vance, 1996; Sheng et al., 1996). When the hydrophobicity of the clay is increased, the adsorption of hydrophobic molecules is expected to increase and yield a slower release in aqueous solutions, extending the herbicidal activity for a longer time under field conditions (Wagner et al., 1994). The success of this approach was shown by El-Nahhal et al. (1998) with the herbicide alachlor. In addition, we have also prepared formulations based on polyoxoaluminum-pillared clays. The release of alachlor from an Al-pillared clay CRF and its subsequent transport in soil columns showed that pillared clays can be used for controlled release of herbicides (Gerstl et al., 1998).

\section{MATERIALS AND METHODS}

Materials. The clays used were a standard montmorillonite (SWy-1) (Van Olphen and Fripiat, 1979) supplied by the Clay Minerals Society, Y unclillos sepiolite (Ruiz-Hitzky and Casal, 1985) supplied by Tolsa S. A. (Madrid, Spain), and an aluminapillared montmorillonite (ALFULCAT 2C) (J ones et al., 1997; Mishael et al., 1999) supplied by the National Technical University of Athens, Greece. Analytical and technical grade norflurazon, 99.9 and $97.8 \%$ purity, respectively, were kindly 


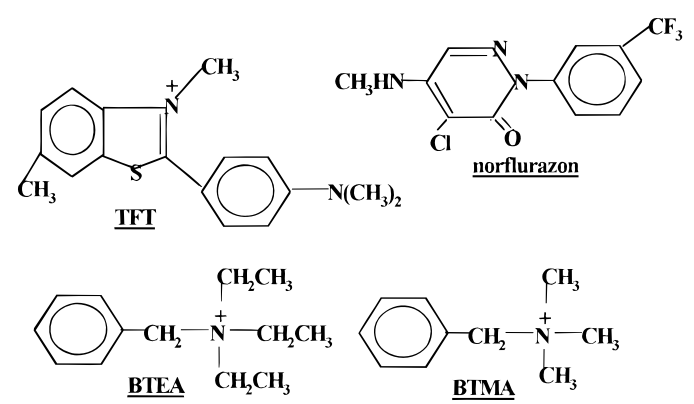

Figure 1. Structural formulas of the molecules used.

supplied by Novartis A. G. (Basel, Switzerland). Benzyltrimethylammonium (BTMA), benzyltriethylammonium (BTEA), and thioflavin-T were purchased from Sigma-Aldrich (Sigma Chemical Co., St. Louis, MO); HPLC acetonitrile and HPLC water were from Merck (Darmstadt, Germany). The structural formulas of the herbicide and the organic cations are shown in Figure 1. The soil used was a sandy loam soil collected from 0 to $30 \mathrm{~cm}$ depth at the Faculty's Experimental Farm in Rehovot. Green foxtail (Setaria viridis L. Beauvois) and wheat (Triticum aestivum L., Cv. Ariel) were used as test plants.

Preparation of the Organo-Clay Complexes. The organo-clays were prepared by dropwise addition of aliquots of $10^{-1} \mathrm{M}$ of BTMA and BTEA and $10^{-2} \mathrm{M}$ of TFT to aqueous suspension of the clay under continuous stirring. The final suspension was $1 \%(\mathrm{w} / \mathrm{v})$. After being stirred for $24 \mathrm{~h}$, the suspensions were centrifuged at $20000 \mathrm{~g}$ for $20 \mathrm{~min}$, the supernatant was discarded, and the samples were freeze-dried. The final loads were $0.2,0.5$, and $0.8 \mathrm{mmol} / \mathrm{g}$ for each organic cation. Mixture loads of 0.2 and $0.5 \mathrm{mmol} / \mathrm{g}$ of BTMA and TFT were also prepared.

Adsorption I sotherms of Norflurazon. Norflurazon adsorption isotherms were carried out by adding $20 \mathrm{~mL}$ of aqueous norflurazon solutions ranging from 13.17 to $65.85 \mu \mathrm{M}$ under continuous stirring of $5 \mathrm{~mL}$ of $2.5 \%$ (w/w) clay/organoclay suspension in $30 \mathrm{~mL}$ polycarbonate tubes. After the tubes were shaken for $24 \mathrm{~h}$ at $20 \pm 1{ }^{\circ} \mathrm{C}$, the suspensions were ultracentrifuged at $133680 \mathrm{~g}$ for $1 \mathrm{~h}$ (Centrikon T-1170), and the norflurazon concentration in the supernatant was determined by using a Merck-Hitachi HPLC equipped with fluorescence detector, by the method described by William and Mueller (1994).

Preparation of Formulations. F ormulations from water (denoted by w) were prepared by dissolving technical norflurazon up to the solubility limit, and the solutions were filtered by $0.45 u$ Millipore filters and mixed with clay or organo-clay, with the final suspension being $0.5 \%(\mathrm{w} / \mathrm{w})$. The suspensions were stirred for $24 \mathrm{~h}$ and thereafter centrifuged. The supernatant was discarded, and the pellets were freeze-dried. The a.i. content $(\mathrm{w} / \mathrm{w})$ ranged between 0.28 and $0.70 \%$. F ormulations from acetone (denoted by a) were also prepared for pillared clay and montmorillonite preadsorbed with TFT at $0.5 \mathrm{mmol} / \mathrm{g}$ (TFT 0.5), by dissolving the herbicide in acetone and mixing the solution with the clay, with the final suspension being $3 \%(w / w)$. The solvent was evaporated using a rotavapor, and the same procedure was repeated five times. Part of these formulations were washed with ethanol $(2 \% \mathrm{w} / \mathrm{v})$ by using syntaglass filters (denoted by ae). The a.i. content (w/w) was 8.64 and $11.08 \%$ for TFT 0.5 (ae) and PC (ae), respectively.

Infrared Spectra. Infrared spectroscopy was used to examine interactions between norflurazon and the clays, PC, and montmorillonite preadsorbed with different organic cations. I nfrared spectra were obtained by using $\mathrm{KBr}$ pellets with a Nicolet Magna IR-550. The spectra were recorded at room temperature in the range of $400-4000 \mathrm{~cm}^{-1}$.

Release Studies. Release of norflurazon from PC and TFT 0.5 was followed under conditions of the adsorption experiments. After reaching equilibrium, the supernatant was removed, letting the clay dry, and same volume of distilled water was added. The tubes were centrifuged after 1 and 24

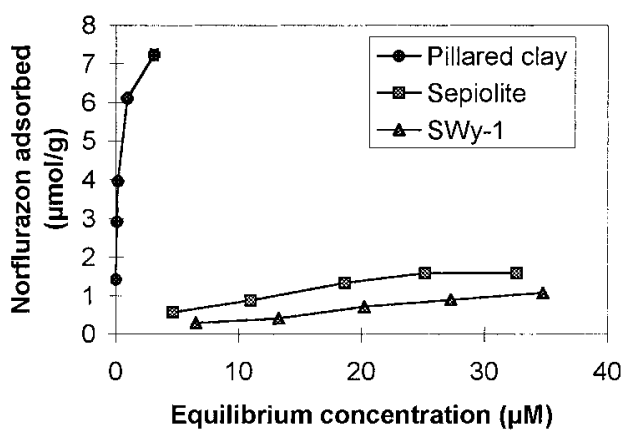

Figure 2. Adsorption isotherms of norflurazon on pillared clay, sepiolite and montmorillonite.

$\mathrm{h}$ and 3 and 7 days, and the content of norflurazon in the supernatant was determined. Release of noflurazon from PC and TFT 0.5 acetone formulations was followed by using dialysis bags containing the formulations in $500 \mathrm{~mL}$ of water, the final concentration of norflurazon in the system being 65.85 $\mu \mathrm{M}$, and sampling for $24,72,120$, and $168 \mathrm{~h}$. The experiments were done in duplicate.

Leaching Studies in Soil Columns. Tin columns $(10 \times$ $10 \times 20 \mathrm{~cm}$ ) were filled with Rehovot soil and sprayed with the commercial and organo-clay formulations at $1 \mathrm{~kg}$ a.i. ha ${ }^{-1}$. The columns were carefully irrigated with $500 \mathrm{~m}^{3} \mathrm{ha}^{-1}$, applied in 10 portions, and left for $24 \mathrm{~h}$ for equilibration. The columns were sliced along their lengths forming two pots of $10 \times 5 \times$ $20 \mathrm{~cm}$. Green foxtail and wheat were sown in two rows in each new pot. Herbicide leaching was determined after 14 days by measuring the bleached plants along the length from the top of the column. The bleaching intensity was obtained by measuring the chl orophyll content every two centimeters and determining the inhibition percentage in relation to the chlorophyll content for the same length of control soil columns (no herbicide added). The chl orophyll content was determined by cutting the fresh shoot of wheat plants and extracted with $4 \mathrm{~mL}$ of $\mathrm{N}, \mathrm{N}$-dimethylformamide (DMF). The solutions were incubated for $48 \mathrm{~h}$, and the chlorophyll ( $\mathrm{a}$ and b) content was measured by vis spectroscopy at 664 and $647 \mathrm{~nm}$ and related to the weight of the fresh shoot.

The experiments in soil columns were always done in triplicate for each formulation.

Data Analysis. The bleaching lengths of the different formulations through the soil columns were subjected to analysis of variance and the main effects and the interactions were tested for significance using repeated measures ANOVA. The means of effects of different formulations were compared by Student's t test $(a=0.05)$, following one-way ANOVA. The inhibition percentage under each length studied was analyzed by using the standard error as a pool ed estimation.

\section{RESULTS AND DISCUSSION}

Norflurazon Adsorption. Adsorption isotherms of norflurazon on montmorillonite, sepiolite and pillared clay (PC) are shown in Figure 2. Unlike the small adsorbed fractions of added norflurazon on sepiolite and montmorillonite, most of the added norflurazon was adsorbed on the pillared clay. Adsorption percentages range from 13.3 to 42.2, from 19.0 to 38.1, and from 92.1 to $100 \%$ for montmorillonite, sepiol ite and PC, respectively. The adsorption of neutral molecules on clays can be described by using the Scatchard equation which is equivalent to the Langmuir equation (Nir et al., 1994; Rytwo et al., 1998). The binding coefficients obtained (k) that are a measure of the affinity of the herbicide to the organo-clay, are listed in Table 1 . The highest binding coefficient corresponds to adsorption on PC, which is two orders of magnitude higher than that for montmorillonite. 


\begin{tabular}{|c|c|c|}
\hline system & $k\left(M^{-1}\right)$ & $\mathrm{R}^{2}$ \\
\hline SWy-1 & 40 & 0.98 \\
\hline sepiolite & 73 & 0.77 \\
\hline pillared clay & 5000 & 0.99 \\
\hline SWy-BTMA 0.2 & 115 & 0.99 \\
\hline SWy-BTMA 0.5 & 215 & 0.99 \\
\hline SWy-BTMA 0.8 & 150 & 0.99 \\
\hline SWy-BTEA 0.2 & 130 & 0.99 \\
\hline SWy-BTEA 0.5 & 190 & 1.00 \\
\hline SWY-BTEA 0.8 & 250 & 0.99 \\
\hline SWy-TFT 0.2 & 800 & 0.98 \\
\hline SWy-TFT 0.5 & 1500 & 0.99 \\
\hline SWy-TFT 0.8 & 50 & 0.91 \\
\hline SWy-BTMA $0.2-T F T 0.5$ & 650 & 0.98 \\
\hline SWy-BTMA 0.5-TFT 0.2 & 400 & 1.00 \\
\hline
\end{tabular}

a The root-mean-square error was within the experimental uncertainty.

Norflurazon adsorption on montmorillonite can occur via ion-dipole interactions of the pyridazinone ring of the herbicide and the cations saturating the interlayer space as described for chloridazone, another related pyridazinone herbicide (Sánchez-Martín and SánchezCamazano, 1987). However, this mechanism cannot account for the high affinity of norflurazon adsorption on PC. Indeed, when the adsorption is normalized to the CEC of the clays for the highest initial concentration used, the ratios obtained increase in the sequence 1.41, 10.53, and $12.06 \mu \mathrm{mol}$ norflurazon adsorbed $/ \mathrm{mmol}$ for SWy-1, sepiolite, and PC, respectively.

In the case of PC, its large porous structure is responsible for the adsorption of norflurazon acting as a zeolite-like molecular sieve (Zielke and Pinnavaia, 1988; Tsvetkov and Mingelgrin, 1990; Gerstl et al., 1998), in addition to its acidic nature, mainly due to its high Lewis acidity (Nolan et al., 1989; Bagshaw and Cooney, 1996). However, norflurazon adsorption on sepiolite is significantly lower than that on PC, despite its larger specific surface area (340 vs $315 \mathrm{~m}^{2} \mathrm{~g}^{-1}$ ) and micropore volume $\left(0.44\right.$ vs $\left.0.33 \mathrm{~cm}^{3} \mathrm{~g}^{-1}\right)$, suggesting that the main mechanism of adsorption on PC is due to the interaction with Lewis acid sites. The Lewis base character of norflurazon is due to the presence of an aromatic ring in its structure and a pyridazinone ring attached to two electron-donor groups (chloride and methylamine) which increase its electronic density in the pyridazinone ring, thus enhancing their Lewis base character. Unpublished results (Leon Margulies, personal communication) show the importance of these two mechanisms, since the adsorption of neutral aromatic compounds on a pillared clay increased in the sequence mesitylene $>$ toluene, which is not in line with their size increase. The presence of a methyl group attached to an aromatic ring will increase the electron density of the ring, due to its positive inductive effect increasing its Lewis base character. This effect will be more pronounced for mesitylene, which has three methyl groups, than that for toluene, with only one methyl group attached to the aromatic ring, and consequently, the adsorption of mesitylene on PC is higher than that for toluene.

Adsorption of norflurazon on montmorillonite preadsorbed with several loads of the organic cations BTMA, BTEA, and TFT increases dramatically when compared to that of montmorillonite (Figure 3; Table 1). The use

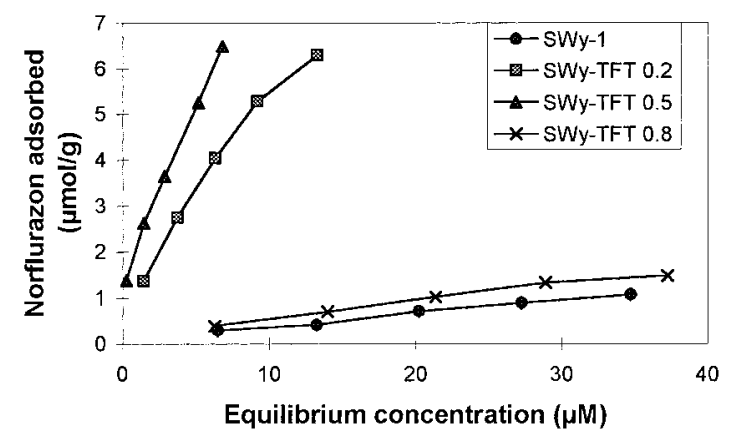

Figure 3. Adsorption isotherms of norflurazon on montmorillonite preloaded with TFT at $0,0.2,0.5$, and $0.8 \mathrm{mmol} / \mathrm{g}$.

of organo-clay enhances the binding coefficient with respect to montmorillonite by up to 6-fold in the cases of BTMA and BTEA, and up to 40-fold for TFT. When trying to improve norflurazon adsorption by using organo-clays that are a mixture of BTMA and TFT, there is no improvement in increasing herbicide adsorption, as shown in the reduction of the binding coefficients with respect to those corresponding to TFT. We interpret the larger binding coefficient for norflurazon adsorption on SWy-TFT than those on SWy-BTMA and BTEA to arise from the different interactions between norflurazon and the organic cation adsorbed on the clay mineral surface. If interactions between the corresponding rings of norflurazon and the organic cations play a role, then it can be expected that the chances for interactions between corresponding rings would be larger in the case of TFT (see Figure 1).

The hydrophilic character of montmorillonite is due to the strongly hydrated exchangeable cation, since the siloxane surface is considered hydrophobic (Sposito and Prost, 1982; Garfinkel-Shweky and Yariv, 1997). The replacement of the interlayer cations by less hydrated small quaternary ammonium cations increases the hydrophobicity of the clay and the adsorption of nonionic organic compounds (J aynes and Boyd, 1991; Smith and Galan, 1995). Stevens et al. (1996) deduced by infrared studies that the sorption of arenes primarily occurred on the siloxane surface. However, additional mechanisms should be operating as can be inferred from Figure 3 and Table 1, since the highest adsorption of norflurazon does not take place on the clay preloaded with the organic cation up to the CEC, but at a loading of $5 / 8$ of the CEC. Xu et al. (1997) also observed that the adsorption capacity of trimethyl phenylammonium (TM PA)-smectite for aromatic hydrocarbons increased dramatically when the fraction of exchange sites occupied by TMPA reached $65-75 \%$ of the CEC, and further increase of TMPA loading decreased its adsorption capacity.

The adsorption of the herbicide on the organo-clay should also be dependent on the existence of specific interactions between the phenyl rings of the herbicide and the organic cation preloading the clay. Nir et al. (2000) have demonstrated enhanced pair interactions of the phenyl rings between hydrophobic herbicides and the organic cation BTMA as compared to BTEA by using model calculations. In the latter study, it was noted that BTMA has a slightly higher binding coefficient $(\bar{K})$ for the formation of charged complexes consisting of one surface site and two organic cations than that of BTEA (20 vs $5 \mathrm{M}^{-1}$, respectively) (Polubesova et al., 1997). The calculated percents of charged complexes are 2 and 14$18 \%$ for SWy-BTMA 0.5 and $0.8 \mathrm{mmol} / \mathrm{g}$, respectively, 


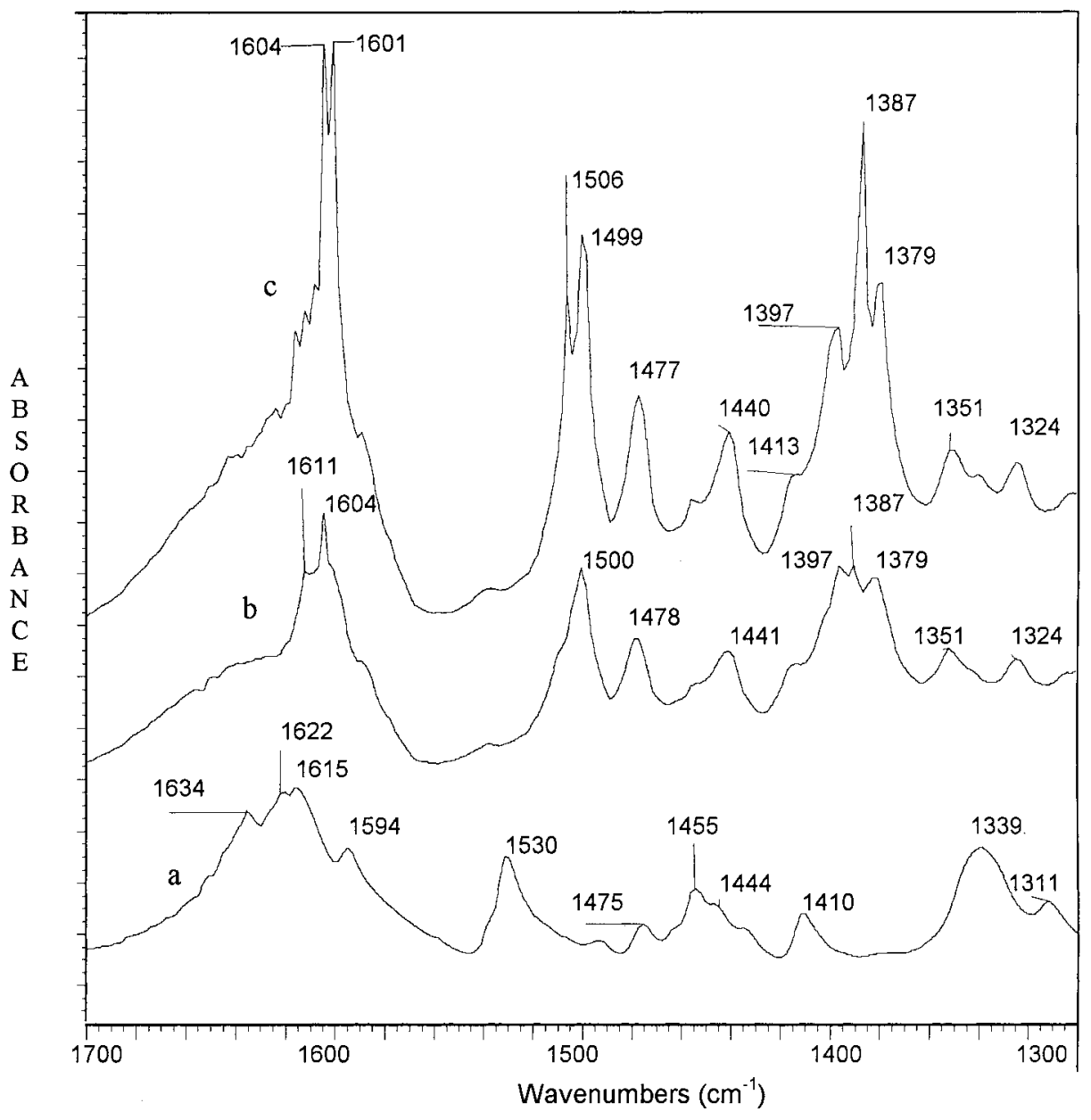

Figure 4. FTIR absorption spectra of free norflurazon (a), SWy-TFT 0.5 (b), and norflurazon adsorbed on the previous organoclay complex (c).

and 0.3 and $6-7 \%$ for SWy-BTEA 0.5 and $0.8 \mathrm{mmol} / \mathrm{g}$, respectively. Consequently, the interactions of the phen$y$ l rings of the herbicide and those of the organic cations would be less favored for the organic cation loading of 0.8 than that of $0.5 \mathrm{mmol} / \mathrm{g}$. However, this effect is not so drastic for BTEA due to the small percentage of double complex, which is overcome by the enhanced hydrophobicity of the organo-clay complex, promoting herbicide adsorption. Norflurazon adsorption on SWyTFT shows the same pattern as that on SWy-BTMA. By using the same binding coefficients for TFT on montmorillonite as those in Margulies et al. (1988) (K $=10^{9} ; \overline{\mathrm{K}}=1.5 \times 10^{6}$ ), the respective percentages of double complexes on SWy-TFT 0.5 and $0.8 \mathrm{mmol} / \mathrm{g}$ are 0 and $7.2-13.4 \%$, respectively, where the range of values reflects the uncertainty in the binding coefficients.

FTIR Results. Detailed information about the mechanisms involved in the interaction of the herbicide and the organo-clays can be obtained by using infrared spectroscopy. However, only the organo-clay SWy-TFT 0.5 provided information about the modes of interaction, because norflurazon loading on the other organo-clays was not sufficient. In the case of pillared clay, a slight broadening of the absorption bands corresponding to the clay itself was observed, which obscured additional information on the bands of norflurazon.

Figure 4 shows the spectra of norflurazon in its free form (F igure 4a), the organo-clay SWy-TFT 0.5 (Figure 4b), and the organo-clay formulation resulting from the adsorption of the herbicide on the organo-clay (Figure 4c). The most rel evant features of the norflurazon-free spectrum are the absorption bands due to the stretching frequency of the $\mathrm{C}=\mathrm{O}$ group at $1622 \mathrm{~cm}^{-1}$ and the vibration modes of the pyridazinone ring at 1410 and $1530 \mathrm{~cm}^{-1}$ (Sánchez-Martín and Sánchez-Camazano, 1987). The absorption bands at 1615, 1475, and 1455 $\mathrm{cm}^{-1}$ can be assigned to skel etal breathing modes of the phenyl ring, and at $1339 \mathrm{~cm}^{-1}$ to $\mathrm{C}$ aromatic-N stretching vibration.

In the case of the organo-clay complex, the spectrum shows absorption bands that are due to the following: the thiazol ring at 1500 and $1387 \mathrm{~cm}^{-1}$ (Pouchert, 1981); the breathing modes of phenyl ring at 1604 and 1478 $\mathrm{cm}^{-1}$; the symmetrical mode of the $\mathrm{C}-\mathrm{H}$ deformation frequencies of the gem-methyl groups attached to $\mathrm{N}$ at 1379 and $1397 \mathrm{~cm}^{-1}$; and the $\mathrm{C}-\mathrm{H}$ deformation band of methyl attached to $\mathrm{N}$ at $1441 \mathrm{~cm}^{-1}$.

When norflurazon is adsorbed on the organo-clay (Figure 4c), there are changes in the vibration modes of the organic cation adsorbed on the clay, although it is not possible to distinguish bands due to norflurazon that could reveal the groups involved in its interaction with the organo-clay. The new striking features indicating changes in the vibration modes are the shift of the band at $1500 \mathrm{~cm}^{-1}$, an increase in the intensity of the band at $1387 \mathrm{~cm}^{-1}$ and the appearance of a second band corresponding to the degenerate pair of the breathing mode of the phenyl ring at $1601 \mathrm{~cm}^{-1}$. This last feature is especially relevant and is indicative of $\pi-\pi^{*}$ interac- 
Table 2. Norflurazon Leaching Depth of the Commercial and Clay/Organo-Clay Formulations Prepared in Water Medium (w), as Measured by Their Effects on Green Foxtail Shoot Bleaching

\begin{tabular}{cc}
\hline formulation & leaching length $(\mathrm{cm})$ \\
\hline commercial & $14.3^{\mathrm{a}}$ \\
SWy-BTMA 0.5 (w) & $12.2^{\mathrm{a}, \mathrm{b}}$ \\
SWy-BTMA 0.2 (w) & $12.5^{\mathrm{a}, \mathrm{b}}$ \\
PC (w) & $11.3^{\mathrm{b}}$ \\
SWy-TFT 0.2 (w) & $11.1^{\mathrm{b}}$ \\
SWy-TFT 0.5 (w) & $10.1^{\mathrm{b}}$
\end{tabular}

a,b Means with the same letter are not significantly different at the $5 \%$ level as determined by Student's multiple range test.

tions between aromatic moieties of the herbicide and the organic cation. The interaction between the $\pi$ cloud of norflurazon and the aromatic ring system of TFT intensifies this band, which is seen as a separate band of comparable intensity to the other component of the doublet. Hence, the FTIR results support the existence of interactions between the rings of norflurazon and TFT.

Leaching Studies. Results of greenhouse experiments using soil columns and bioassays for the commercial formulation, as well as those based on clays prepared in water medium, are given in Table 2. Formulations based on montmorillonite-BTEA were not included in this study because of the similar binding coefficient of norflurazon to montmorillonite-BTMA (Table 1). It can be seen in Table 2 that the commercial formulation leaches up to a depth of $14 \mathrm{~cm}$ in the column, in comparison to the other formulations whose average is about $11 \mathrm{~cm}$, amounting to a decrease in 15\% of the leaching depth. However, the statistical analysis indicates that only the formulations prepared on SWyTFT and PC yield significantly smal ler leaching depths than that of the commercial formulation. No significant difference was noticed between norflurazon formulations based on PC or montmorillonite-TFT.

These features are in agreement with the previous results obtained in norflurazon adsorption experiments. The binding coefficients in Table 1 indicate that the interaction between norflurazon molecules and BTMAorgano-clays is very weak in comparison to its interaction to PC or montmorillonite-TFT. Our conclusion is that the reduced leaching observed is due to a slow release of the herbicide that is related to the strong interaction between the herbicide molecules and the organo-clay or PC. Indeed, when the release of norflurazon was followed under conditions of the adsorption experiments by removing the supernatant, letting the clay dry, and adding the same volume of water, norflurazon desorption approached equilibrium only after 3 days, giving $12 \%$ and $22 \%$ rel ease for PC and TFT 0.5 , respectively. The strength of the interaction between the clay/organo-clays and the herbicide would be a function of the molecular characteristics of the herbicide and the organic cation. El-Nahhal et al. (1998) found that the rate of release of the hydrophobic herbicide alachlor on an organo-clay loaded with aromatic organic cations increased when increasing the length of alkyl chain of the organic cation. The slowest release was obtained with the smallest organic cation used, BTMA. In our case, the use of a larger organic aromatic cation, TFT, was more effective than BTMA. This can be due to its larger aromaticity that will enhance $\pi-\pi^{*}$ interactions, which are the main ones promoting the adsorption of the herbicide on the organo-clay, in accord with the IR results.
Table 3. Norflurazon Leaching Depth of PC and SWy-TFT 0.5-Based Formulations Prepared in Water (w) and Acetone (a) in Comparison with the Commercial Formulation, as Measured by Their Effects on Green Foxtail Shoot Bleaching

\begin{tabular}{lc}
\hline \multicolumn{1}{c}{ formulation } & leaching length $(\mathrm{cm})$ \\
\hline commercial & $13.8^{\mathrm{a}}$ \\
PC (a) & $11.7^{\mathrm{b}}$ \\
SWy-TFT 0.5 (a) & $11.2^{\mathrm{b}}$ \\
SWy-TFT 0.5 (w) & $10.3^{\mathrm{b}}$ \\
PC (w) & $10.3^{\mathrm{b}}$
\end{tabular}

a,b Means with the same letter are not significantly different at the $5 \%$ level as determined by Student's multiple range test.
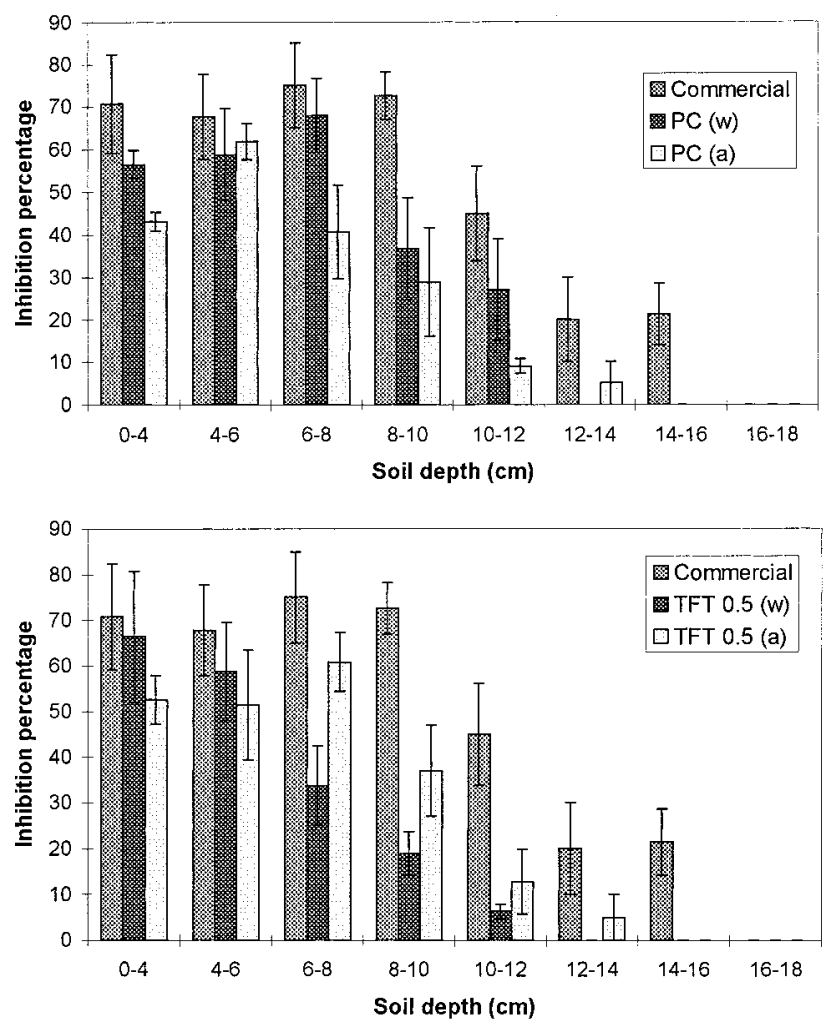

Figure 5. Inhibition percentages of norflurazon formulations based on PC (a) and TFT (b), in comparison with the commercial formulation. The inhibition percentage was obtained from chlorophyll content reduction in wheat shoot.

Table 3 gives the results for another set of experiments carried out by using formulations based on SWyTFT 0.5 and PC that were prepared in water and acetone media. The leaching depth is significantly higher for the commercial formulation than that for the clay-based ones. The statistical analysis shows that there is no difference between the leaching depth of the formulations prepared in acetone and those prepared in water. By considering their average, these formulations reduce norflurazon leaching by about $21 \%$.

For the same set of experiments, the inhibition percentages of norflurazon formulations at different depths were measured by its bleaching effect on wheat shoot (Figure 5). The herbicidal activity of the commercial formulation is about $70 \%$ throughout the first $10 \mathrm{~cm}$ and is still high enough at a depth of $12 \mathrm{~cm}$. The formulations prepared in water and acetone show the same activity for the first $6 \mathrm{~cm}$, which is the depth desired for weed control, with the decrease with the depth for PC (w) and TFT 0.5 (a) being steeper.

The formulations prepared from acetone may exhibit an improvement with respect to those prepared in water 
Table 4. Norflurazon Leaching Depth of PC and SWy-TFT 0.5-Based Formulations Prepared in Acetone Washed with Ethanol (ae) in Comparison with the Commercial Formulation, as Measured by Their Effects on Green Foxtail Shoot Bleaching

\begin{tabular}{lc}
\hline \multicolumn{1}{c}{ formulation } & leaching length $(\mathrm{cm})$ \\
\hline commercial & $17.2^{\mathrm{a}}$ \\
PC (ae) & $14.2^{\mathrm{b}}$ \\
SWy-TFT 0.5 (ae) & $14.6^{\mathrm{b}}$
\end{tabular}

a,b Means with the same letter are not significantly different at the $5 \%$ level as determined by Student's multiple range test.

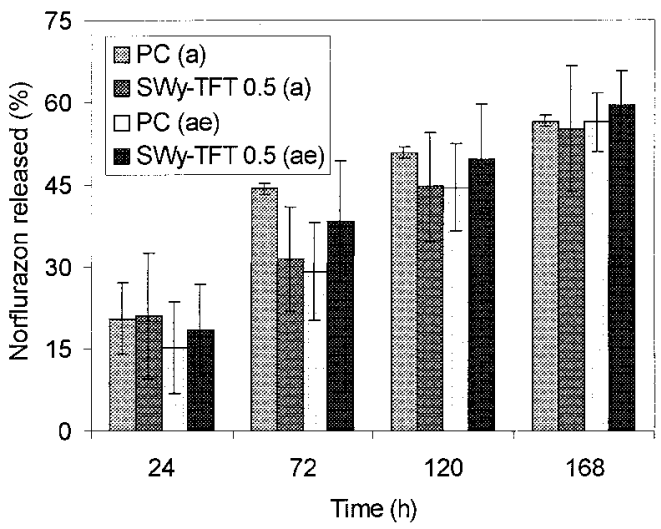

Figure 6. Norflurazon released from formulations prepared in acetone (a) and acetone washed with ethanol (ae) from dialysis bags as a function of time.

(Table 3, Figure 5) since their leaching depths are not significantly different and their bleaching activity with depth is only slightly lower, whereas their a.i. content is about 20-fold higher than that of the (w) formulations. Since some norflurazon molecules from the formulations prepared in acetone could loosely be attached to the clay mineral surface, formulations from acetone washed with ethanol were considered. Results of leaching based on bleaching activity are shown in Table 4. The commercial formulation leaches up to $17.2 \mathrm{~cm}$, instead of $13.8 \mathrm{~cm}$ as reported in Tables 2 and 3 . This can be due to the longer elapsed time (48 h) between the irrigation and sowing in the columns. The results from Table 4 indicate that the formulations prepared in acetone washed with ethanol are significantly different from the commercial one, and reduce leaching by $16 \%$. When comparing these results to those for formulations prepared in acetone in Table 3, the formulations from acetone washed with ethanol did not give an improvement. The release experiments in Figure 6 show a parallelism under drastic conditions between the formulations in acetone and those from acetone washed with ethanol. The results in Figure 6 show that the percent of norflurazon released from the formulation PC (a) continues to increase for 7 days under conditions of large clay dilution $(0.013 \%)$. The same trend is also observed for the other formulations, but due to the experimental uncertainties, it can be stated that complete rel ease (up to equilibrium) requires at least 3 days. During irrigation, the added herbicide formulations are exposed to water for significantly shorter periods, and the clay particles are at larger concentrations than that in Figure 6 . Thus, these release results imply that low release of norflurazon from the new formulations is expected in the column experiments.

The development of controlled release formulations should create a compromise between the depth of leaching and the herbicidal activity in the top soil layer.
An extremely low rate of rel ease from the formulations can reduce substantially the amount of herbicide available for leaching and lead to better long-term weed control, but the rate applied should be larger for getting the threshold concentration needed to get weed control at the top soil layer during the early events. The formulations based on pillared clay and organo-clays (TFT 0.5) show slow release, reducing leaching, and good herbicidal activity at the optimal depth for weed control.

\section{ACKNOWLEDGMENT}

This research was supported by Grant G-045-95 from G.I.F., the German-Israeli Foundation for Scientific Research and Development. T.U. acknowledges postdoctoral fellowships from the Spanish Government (Ref. PF 9633975424) and the European Community (program TMR, Contract No. FAIR-BM-970892).

\section{LITERATURE CITED}

Bagshaw, S.; Cooney, R. P. FT-IR analysis of pillared clay pore structure via adsorbed bipyridine surface probe species Appl. Spectrosc. 1996, 50, 1319-1324.

Boydston, R. A. Controlled release starch granule formulations reduce herbicide leaching in soil columns. Weed Technol. 1992, 6, 317-321.

Dailey, O. D.; Dowler, C. C.; Mullinix, B. G. Polymeric microcapsules of the herbicides atrazine and metribuzin: preparation and evaluation of control led rel ease properties. J . Agric. Food Chem. 1993, 41, 1517-1522.

El-Nahhal, Y.; Nir, S.; Polubesova, T.; Margulies, L.; Rubin, B. Leaching, phytotoxicity, and weed control of new formulations of alachlor. J . Agric. Food Chem. 1998, 46, 33053313.

Ferraz, A.; Souza, J . A.; Silva, F. T.; Gonçalves, A. R.; Bruns, R. E.; Cotrim, A. R.; Wilkins, R. M. Controlled release of 2,4-D from granule matrix formulations based on six lignins. J . Agric. Food Chem. 1997, 45, 1001-1005.

Franklin, R. E.; Quisenberry, V. L.; Gosset, B. J .; Murdock, E. C. Selection of herbicide alternatives based on probable leaching to groundwater. Weed Technol. 1994, 8, 6-16.

Garfinkel-Shweky, D.; Yariv, S. The determination of surface basicity of the oxygen planes of expanding clay minerals by acridine orange. J. Colloid Interface Sci. 1997, 188, 168175.

Gerstl, Z.; Nasser, A.; Mingelgrin, U. Controlled release of pesticides into soils from clay-polymer formulations. J. Agric. Food Chem. 1998, 46, 3797-3802.

J aynes W. F.; Boyd, S. A. Hydrophobicity of siloxane surfaces in smectites as revealed by aromatic hydrocarbon adsorption from water. Clays Clay Miner. 1991, 39, 428-436.

J aynes, W. F.; Vance, G. F. BTEX sorption by organo-clays: cosorptive enhancement and equivalence of interlayer complexes. Soil Sci. Soc. Am. J . 1996, 60, 1742-1749.

J ones, W.; Poncelet, G.; Ruiz-Hitzky, E.; Galvan, J . C.; Pomonis, P.; Van Damme, H.; Bergaya, F.; Papayannakos, N.; Gangas, N. TheSynthesis, Characterisation and Application of Pillared Layered Solids (PILCS) Produced in Large Quantities, Synthesis Report of Brite-Euram Contract No. BRE2-CT-0629 of the European Community, 1997.

Kim, J .-H.; Feagley, S. E. Adsorption and leaching of trifluralin, metolachlor, and metribuzin in a commerce soil. J Environ. Sci. Health B 1998, 33, 529-546.

Lo, C.; Merkle, M. G. Factors affecting the phytotoxicity of norflurazon. Weed Sci. 1984, 32, 279-283.

Loukas, Y. L.; Antoniadou-Vyza, E.; Papadaki-Valiraki, A.; Machera, K. G. $\gamma$-Ciclodextrin inclusion complex of a new organophosphorus insecticide. Determination of stability constant with HPLC. J . Agric. Food Chem. 1994, 42, 944948. 
Margulies, L.; Rozen, H.; Nir, S. Model for competitive adsorption of organic cations on clays. Clays Clay Miner. 1988, 36, 270-276.

Mervosh, T. L.; Stoller, E. W.; Simmons, F. W.; Ellsworth, T. R.; Sims, G. Effects of starch encapsulation on clomazone and atrazine movement in soil and clomazone volatilization. Weed Sci. 1995, 43, 445-453.

Mishael, Y. G.; Rytwo G.; Nir S.; Crespin M.; Annabi-Bergaya $\mathrm{F}$.; Van Damme, H. Interactions of monovalent organic cations with pillared clays. J . Colloid Interface Sci. 1999, 209, 123-128.

Nir, S.; Peled, R.; Lee, K. Analysis of particle uptake by cells: Binding to several receptors, equilibration time, endocytosis. Colloids Surf. A 1994, 89, 44-57.

Nir, S.; Undabeytia, T.; Yaron-Marcovich, D.; El-Nahhal, Y.; Polubesova, T.; Serban, C.; Rytwo, G.; Lagaly, G.; Rubin, B. Optimization of adsorption of hydrophobic herbicides on montmorillonite preadsorbed by monovalent organic cations: Interaction between phenyl rings. Environ. Sci. Technol. 2000, 34, 1269-1274.

Nolan, T.; Srinivasan, K. R.; Fogler, S. Dioxon sorption by hydroxy-alumininum-treated days. Clays Clay Miner. 1989, 37, 487-492.

Parsons, D. W.; Witt, J . M. Pesticides in Groundwater in the United States of America: A Report of a 1988 Survey of State Lead Agencies. Oregon State University Extension Service: Corvallis, OR, 1988.

Polubesova, T.; Rytwo, G.; Nir, S.; Serban, C.; Margulies, L. Adsorption of benzyltrimethylammonium and benzyltriethylammonium on montmorillonite: experimental studies and model calculations. Clays Clay Miner. 1997, 45, 834841.

Pouchert, C. J. The Aldrich Library of Infrared Spectra; Aldrich Chemical Co., Inc.; Milwaukee, WI, 1981; pp 1873.

Reddy, K.; Singh, M.; Alva, A. K. Sorption and desorption of diuron and norflurazon in Florida citrus soils. Water, Air, Soil Pollut. 1992, 64, 487-494.

Ruiz-Hitzky E.; Casal, B. E poxide rearrangements on mineral and silico-alumina surfaces. J . Catal. 1985, 92, 291-295.

Rytwo, G.; Nir, S.; Margulies, L.; Casal, B.; Merino, J .; RuizHitzky, E.; Serratosa, J. M. Adsorption of monovalent organic cations on sepiolite: experimental results and model calculations. Clays Clay Miner. 1998, 46, 340-348.

Sánchez-Martín, M.J .; Sánchez-Camazano, M. Adsorption of chloridazone by montmorillonite. Chemosphere 1987, 16, 937-944.

Senseman, S. A.; Lavy, T. L.; Daniel, T. C. Monitoring groundwater for pesticides at selected mixing/loading sites in Arkansas. Environ. Sci. Technol. 1997a, 31, 283-288.
Senseman, S. A.; Lavy, T. L.; Mattice, J . D.; Gbur, E. E.; Skulman, B. W. Trace level pesticide detections in Arkansas surface waters. Environ. Sci. Technol. 1997b, 31, 395-401.

Sheng, G.; Xu, S.; Boyd, S. Mechanism(s) controlling sorption of neutral organic contaminants by surfactant-derived and natural organic matter. Environ. Sci. Technol. 1996, 30, 1553-1557.

Smith, J . A.; Galan, A. Sorption of nonionic organic contaminants to single and dual organic cation bentonites from water. Environ. Sci. Technol. 1995, 29, 685-692.

Sposito, G.; Prost, R. Structure of water adsorbed on smectites. Chem. Rev. 1982, 82, 553-573.

Stevens, J. J .; Anderson S. J .; Boyd, S. FTIR study of competitive water-arene sorption on tetramethylammonium- and trimethylphenylammonium montmorillonites. Clays Clay Miner. 1996, 44, 88-95.

Tsvetkov, F .; Mingelgrin, U .; Lahav, N. Cross-linked hydroxyAl-montmorillonite as a stationary phase in liquid chromatography. Clays Clay Miner. 1990, 38, 380-390.

van Olphen H.; Fripiat, J . J . Data Handbook for Clay Materials and Other Nonmetallic Minerals; Pergamon: Oxford, 1979; p 301.

Wagner, J .; Chen, H.; Brownawell, B. J .; Westall, J . C. Use of cationic surfactants to modify soil surfaces to promote sorption and retard migration of hydrophobic organic compounds. Environ. Sci. Technol. 1994, 28, 231-237.

Wilcut, J. W.; J ordan, D. L.; Vencill, W. K.; Richburg, J . S. Weed management in cotton (Gossypium hirsutum) with soil-applied and post-directed herbicides. Weed Technol. 1997, 11, 221-226.

William, W. T.; Mueller, T. C. Liquid chromatographic determination of norflurazon and its initial metabolite in soil. J . AOAC Int. 1994, 77, 752-755.

William, W. T.; Mueller, T. C.; Hayes, R. M.; Bridges, D. C.; Snipes, C. E. Norflurazon adsorption and dissipation in three southern soils. Weed Sci. 1997, 45, 301-306.

Xu, S.; Sheng, G.; Boyd, A. Use of organoclays in pollution abatement. Adv. Agron. 1997, 59, 25-62.

Zielke, R. C.; Pinnavaia, T.J . Modified clays for the adsorption of environmental toxicants: binding of chlorophenols to pillared, delaminated, and hydroxy-interlayered smectites. Clays Clay Miner. 1988, 36, 403-408.

Received for review J uly 19, 1999. Accepted J uly 12, 2000.

J F 9907945 